\title{
Um filme que pensa sobre si: o político e os fragmentos da história
}

\section{Cristiane Freitas Gutfreind}

Doutora; Pontifícia Universidade Católica do Rio Grande do Sul; Porto Alegre, RS, Brasil cristianefreitas@pucrs.br

\section{Márcio Zanetti Negrini}

Doutorando; Pontifícia Universidade Católica do Rio Grande do Sul; Porto Alegre, RS, Brasil marcioznegrini@gmail.com

\section{Resumo}

Analisamos a montagem de Imagens do Estado Novo 1937-45, de Eduardo Escorel, com o objetivo de observar a atualidade da narrativa, enfatizando os seus aspectos políticos. Examinamos, assim, como fragmentos de imagens utilizados pela decupagem articulam a interação entre o tempo presente e as imagens do Estado Novo. A subjetividade como traço narrativo mostra a reflexão que o filme suscita sobre si, a partir de seu narrador, e de vestígios que revelam o processo de montagem de arquivos. O filme elabora uma forma de pensar o político enquanto manifestação da história no tempo presente, abordando fatos que marcaram a primeira metade do século XX no Brasil.

\section{Palavras-chave}

Filme político. Cinema brasileiro. Estado Novo.

\section{Apresentação}

Propomos analisar Imagens do Estado Novo 1937-45, de Eduardo Escorel (IMAGENS..., 2016), pois esse filme permite uma discussão entre imagens, contrapondo a história oficial. Produz, assim, sua versão de um período da história política brasileira por meio da montagem de arquivos. Para isso, observamos fragmentos da narrativa em vista de como sua decupagem articula a interação entre o tempo presente e as imagens do Estado Novo. Buscamos, portanto, compreender as evocações do passado na perspectiva de questões que o filme suscita à atualidade. 
O documentário de 225 minutos é um trabalho realizado por 12 anos de pesquisa. Nessa narrativa, incidem excertos de arquivos, que são imagens de propaganda do regime varguista, isto é, cinejornais. Além disso, são incluídos cinejornais estrangeiros, trechos de filmes do cotidiano urbano e familiar daquela época, fotografias, cartas e, também, o ponto de vista íntimo de Getúlio Vargas a partir do seu diário. Ao articular esses arquivos, o narrador em off, Eduardo Escorel, reflete sobre sua montagem e as lacunas da história.

No filme, o Estado Novo é narrado com base em grandes fatos da política brasileira junto às singularidades dessa experiência histórica. A consolidação de um governo autoritário no Brasil e suas características internas também são apresentadas em relação aos marcos da história política internacional. Notadamente, a ascensão do nazifascismo na Europa da primeira metade do século XX e a simpatia dedicada a ele pelo Brasil liderado por Getúlio Vargas.

Os aspectos estético-formais da narrativa constroem uma perspectiva crítica ao regime autoritário de Vargas, partindo de uma narração do próprio diretor, que coloca em questão as imagens. 0 filme político apresenta-se por sobreposições da história política brasileira e pela reflexão do narrador quanto à criação de sua versão dessa história. Esse é um traço da subjetividade que aproxima a narrativa de um questionamento a respeito do filme político na atualidade.

Podemos afirmar que as representações do passado, do presente e, talvez, do futuro, dependem da época e do contexto de realização dos filmes. A convocação do passado, frequentemente, é tida como uma forma de pensar o presente. Em meio ao momento de crise democrática pelo qual passamos no Brasil atualmente, em que somos, segundo Alain Badiou (2010), "[...]dominados por um historicismo melancólico, em que existe um puro efeito de passado[...]" (BADIOU, 2010, p. 376), Imagens do Estado Novo 1937-45 merece especial atenção.

A história pode ser narrada por períodos abrangentes, intervalos de tempo em que as fronteiras costumam ser nebulosas. Há revoluções, golpes, sucessões de dias e noites emblemáticos com que se produz grandes narrativas sobre as épocas e seus povos. Mas, o que contrapõe a relativa generalidade dos conjuntos de fatos e documentos é a impureza e a impossibilidade de completude intrínsecas à narrativa histórica.

Uma grande narração historiográfica como, por exemplo, aquela que cria abrangência quanto aos acontecimentos políticos de um país, é por natureza fragmentária, lacunar. Naturalmente incompleta pela potencialidade dos pequenos fragmentos de imagens 
que a constituem. Há, assim, uma ambivalência constitutiva da história, pelo entremeio das narrativas generalistas e particulares. Para Siegfried Kracauer (2010), essa é a cumplicidade intrínseca do cinema diante do pensamento no tempo histórico.

Segundo Kracauer (2010), os filmes possibilitam realizar um o jogo entre aproximações e distanciamentos. Isso é produzido pelo sujeito narrador que, na montagem fílmica, simultaneamente, é aquele que vê e é olhado pela história. A realidade, assim, pode ser compreendida a partir do movimento das imagens do cinema. Trata-se do deslocamento entre acontecimentos históricos e imagens que revelam detalhes ainda ocultos, embora presentes na experiência com o tempo.

Os movimentos entre a historiografia de fatos políticos e as imagens dos filmes constituem, para Kracauer (2010), o limiar em que acontece a história. Em outras palavras, os filmes são a simultaneidade entre a forma e a realidade do mundo físico. Isso oferece ao observador uma espécie de distanciamento aproximado, tornando-o mediador dos interstícios por onde transitam singularidades de pequenas existências que colidem com as abrangências históricas.

Outra consequência do ponto de vista de Kracauer (2001) para a análise que propomos, é o fato de que o documentário e a ficção são designações de estilo, não de natureza dos filmes, porque a "materialidade física" que os constituiu é a mesma que habita o mundo (KRACAUER, 2001, p. 312). Além disso, para o autor, ao reunir fragmentos da experiência física com o tempo, a montagem cinematográfica relaciona-se com a própria concepção de história.

Desse modo, a narrativa que analisamos se constitui como uma versão da história política brasileira e, especialmente, apresenta-se dessa forma na medida em que reflete sobre o seu processo de montagem. O filme Imagens do Estado Novo 1937-45, portanto, evidencia-se em uma articulação própria à ideia de história que compreendemos segundo Siegfried Kracauer (2010).

Os filmes montados com base em materiais de arquivos, para Vincent Pinel (2008), apresentam documentos que oferecem a releitura dos fatos com a finalidade de criar um novo olhar para a história. Segundo o autor, “[...] o filme de montagem ${ }^{1}$ joga com uma dupla temporalidade, situando as imagens de ontem no seio de uma perspectiva histórica

\footnotetext{
${ }^{1}$ Na tipologia fílmica de Vincent Pinel (2008), os filmes de montagem são entendidos como narrativas produzidas por meio de imagens e sons de arquivos.
} 
obviamente subjetiva [...]" (PINEL, 2008, p. 199, tradução nossa²). 0 caráter de documento do fragmento fílmico é reconfigurado, isto é, o filme de arquivo se torna ele próprio um documento, que cria uma nova legibilidade da história.

Para Georges Didi-Huberman (2010, 2012), a história figura por colisões entre imagens, em um ato criativo que dá ao arquivo um novo estatuto. Se outrora, uma imagem servira, por exemplo, a um regime autoritário, ao ser deslocada, produz outro circuito sensível de significações provisórias - de criação histórica. Segundo o autor, os deslocamentos e novos arranjos dos arquivos não atribui a eles uma síntese totalizante, pois é no movimento das imagens no tempo que acontecem os choques que resultam em fraturas, produzindo, assim, a perda. A história não é unívoca; são em suas brechas, em suas oscilações que os arquivos deslocam sentidos preconcebidos.

No caso de Imagens do Estado Novo 1937-45, o narrador questiona a possibilidade de se fazer um filme a partir de imagens que serviram ao regime estado-novista. É apresentado um ponto de vista do filme diante daquele que o olha. Com isso, a narrativa propõe-se a refletir o autoritarismo como elemento constitutivo de parte das imagens que utiliza na montagem. Uma nova implicação imagética da história é mobilizada e outra teia de sentidos é criada entre as imagens.

A montagem do filme realiza-se por movimentos de aproximação e distanciamento. Os fatos históricos da política brasileira são apresentados para, em seguida, serem confrontados com trechos do diário pessoal de Getúlio. Além dessa justaposição com a intimidade do ex-presidente, o filme produz uma inflexão sobre si mesmo, ou seja, coloca-se em primeiro plano. Com isso, evidencia sua singularidade como construção narrativa de uma versão de fatos da política brasileira; sugere as imagens que faltam, portanto, aproxima o espectador das lacunas da história.

Em suma, nossa abordagem teórico-metodológica compreende que, no filme, os arquivos de imagens e sons manifestam-se por suas atualidades. A relação entre essas imagens e a narrativa sugere um movimento de escavação, como aquele proposto por Walter Benjamin (2006). Trata-se de deslocar fragmentos da montagem para, dessa forma, ver suas marcas na história. Como um objeto que, ao ser escavado, deixa na terra seu semblante. A face da imagem que resta marcada no filme representa seu novo lugar na

\footnotetext{
${ }^{2}$ No original: [...] la película de monataje juega con una doble temporalidade, situando las imágenes de ayer en el seno de una perspectiva histórica evidentemente subjetiva [...] (PINEL, 2008, p. 199).
} 
história, sua atualidade. As imagens incidem para além de periodizações e fatos objetivos, pois entrelaçam experiências políticas brasileiras de ontem e de hoje.

\section{0 filme político: relações entre o presente e o passado}

A representação de momentos de ruptura decisivos na história está no cerne do cinema, que estabelece uma posição intrínseca entre o artifício e a realidade. Nota-se isso no que André Bazin (2014) definiu como a "ontologia do cinema" e, também, na sua capacidade de alcançar o público, possibilitando encontrar personagens típicos e excessivos, envoltos em conflitos históricos - como é o caso de Imagens do Estado Novo 1937-45.

Essa temática que relaciona a imagem com acontecimentos transformadores da vida social, perpassa toda a história do cinema e se atualiza de acordo com as modificações políticas e ideológicas a cada sobressalto da história. E alguns gêneros do cinema, como o filme político, são, segundo Alain Badiou (2010), gêneros éticos, pois têm a capacidade de dialogar com o universo humano por meio de mitos morais. É nesse sentido que nos interessamos pelo filme político que, segundo Vincent Pinel (2000), tem como tema principal a maneira como é governado um Estado e o exercício do poder, a sua conquista e a denúncia dos seus excessos.

Podemos dizer, assim, que o político em Imagens do Estado Novo 1937-45 manifestase sob dois aspectos. Primeiro, por sua temática abordar fatos históricos da política brasileira, especialmente, quanto à consolidação de um regime autocrático que, com diferentes nuanças, duraria 15 anos. Segundo, por sua montagem mobilizar o espectador quanto às parcialidades de versões construídas para a história, com vistas ao tempo presente.

De acordo com Boris Fausto (2015), desde a Revolução de 19303, o Brasil foi governado por Getúlio Vargas sob estados de exceção - com um breve interlúdio entre 1934

\footnotetext{
3 golpe civil-militar que se autonomeou Revolução de 30 deu lugar a um grupo oligárquico periférico - formado principalmente por Rio Grande do Sul, Paraíba e parte de Minas Gerais - em detrimento de um grupo oligárquico hegemônico que alternava o Poder Executivo nacional durante a Primeira República (entre 1889 e 1930). Essa coalização era composta por São Paulo e Minas Gerais, com o apoio de outros estados, favorecidos pelas candidaturas alternadas entre SP e MG. Foi pelo desentendimento no âmbito desse grupo hegemônico que se construiu um cenário favorável à ascensão dos revolucionários de 1930, tendo como um de seus líderes, o mais emblemático, Getúlio Vargas (FAUSTO, 2015).
} 
e 19354. Tomando-se o argumento de refrear a iminência de sublevações comunistas no país, por vezes, fantasiosas, a segurança nacional foi utilizada como pretexto de ações arbitrárias do Estado, consolidando o golpe que instituiu o Estado Novo em 1937.

Conforme escreveu Paulo Sérgio Pinheiro (2001), os 15 anos em que Getúlio Vargas comandou o Brasil representaram o continuísmo autoritário da Primeira República (entre 1889 e 1930). Além disso, de acordo com Pinheiro (2001), ao final da era Vargas, a redemocratização de 1945 articulara-se com base em instituições autoritárias.

Em última análise, segundo Pinheiro (2001), a abertura democrática após o regime militar - de forma semelhante ao final do Estado Novo - realizou-se pela manutenção institucional do autoritarismo. Isso é representado, sobretudo, pela coação policialesca da população pobre e da eficiência judiciária restrita à elite econômica. Para o autor, a consequência disso é o autoritarismo intrínseco à sociedade brasileira e manifesto em seu cotidiano pela naturalização da violência de Estado.

Nesse sentido, observamos que Imagens do Estado Novo 1937-45 sugere um questionamento sobre o autoritarismo, a partir das relações entre o presente e o passado que o narrador exercita em sua montagem. As nuanças que produz ao aludir as lacunas da história provocam pensar o que resta do autoritarismo na atualidade brasileira. Para isso, utiliza, entre outras, imagens de filmes de família e de cinegrafistas amadores, que registraram o cotidiano das ruas no momento de estabilização do Estado Novo.

Desse modo, indaga o que é visto pelas imagens, mas não é registrado em arquivos escritos. Por exemplo, há afirmações presentes no diário de Getúlio Vargas, mas as imagens mostram um outro rumo dos fatos. É assim que a montagem, criada por meio de agenciamentos visuais e sonoros, revela momentos fundamentais da história brasileira, como a instauração do governo ditatorial, período de grandes transformações políticas e sociais no país, possibilitando uma reflexão sobre a herança da ditadura varguista.

Ao mesmo tempo em que Getúlio Vargas foi um ditador, são inegáveis as transformações que o país viveu ao longo dos 15 anos sob o seu comando. Durante o Estado

\footnotetext{
${ }^{4}$ Em 1934, Getúlio Vargas tornou-se presidente por eleição indireta realizada em Assembleia Constituinte. Com o final do Governo Provisório (vigente entre 1930 e 1934), o Governo Constitucional possibilitaria a realização de eleições diretas à presidência em 1938 - fato que não ocorreu em virtude do golpe civil-militar, que instituiu o Estado Novo em 10 de novembro de 1937, dando fim à abertura democrática. Durante os 15 anos do que se convencionou chamar de era Vargas, por apenas alguns meses, entre 16 de julho de 1934 e 04 de abril de 1935, o país não estaria sob estado de exceção. 0 ano de 1935 é emblemático, pois lançou-se a Aliança Nacional Libertadora (ANL), que visava participar da redemocratização, embora influenciada pelo Partido Comunista Brasileiro, que era mantido na ilegalidade. A ANL logo seria dissolvida e os insurgentes sobrepujados. Getúlio Vargas sancionou a Lei de Segurança Nacional, dispositivo que abandonava garantias processuais diante do que fosse considerado como nocivo aos propósitos do Estado. Em resumo, o que se entendia por ações comunistas, fossem concretas, ou fossem fantasiosas, serviam aos interesses autoritários do governo. Nesse período, houve o endurecimento da repressão e a tortura foi institucionalizada (FAUSTO, 2006).
} 
Novo, consolidaram-se as leis trabalhistas decretadas no início do Governo Provisório. Nesse período, o desenvolvimento social e econômico foi acentuado e o Brasil deixaria de ser um país eminentemente rural, dando cada vez mais espaço a uma classe trabalhadora urbana.

O Estado Novo, portanto, constituiu-se pela ambivalência entre aquilo que foi um regime discricionário e as condições que produziu para a atividade democrática entre 1945 e 1964 - com desdobramentos do final da Ditadura Militar5 até a atualidade (GOMES, 2014). Essa ambiguidade mobiliza a refletir quanto à parcialidade de versões da história. A biografia de Getúlio Vargas relaciona-se com esse fato, na medida em que seu diário oferece um elo que contrapõe o íntimo ao discurso oficial do Estado Novo. A atualidade do filme, em meio a uma nostalgia da história, sustenta-se na ideia de revelar a herança do político no social e em propor uma discussão da própria imagem, uma construção do passado que se reflete no presente.

\section{0 político em um filme que pensa sobre si}

Eduardo Escorel já havia realizado uma trilogia com a temática da era Vargas: 1930 Tempo de revolução, 32 - A guerra civil e 35 - $O$ assalto ao poder ${ }^{6}$. Esses filmes tratavam da ascensão de Getúlio Vargas à Presidência e a sua consolidação no poder (ERA..., 2016). Em Imagens do Estado Novo (2016), o período escolhido é de 1937 a 1945, ou seja, a narrativa centra-se na consolidação da ditadura.

0 filme foi realizado tendo como base pesquisas em arquivos dos cinejornais produzidos pelo regime do Estado Novo brasileiro, de cinejornais de governos estrangeiros - especialmente dos Países do Eixo e dos Aliados na Segunda Guerra Mundial -, filmes de atualidades, filmes domésticos - incluindo os de cinegrafistas amadores que registraram o cotidiano das ruas - imagens de manuscritos oficiais, recortes de jornais da época, fotografias do período, cartas endereçadas ao presidente e, também, trechos do diário íntimo de Getúlio Vargas.

Neste ponto, interessa-nos compreender as reconfigurações que o filme produz a partir desses arquivos, ao mesmo tempo em que pensa a sua própria montagem, mostrandose, assim, como um filme político que trata do histórico, mas em diálogo com o presente.

${ }^{5}$ Entre 1964 e 1985.

${ }^{6}$ Em 2016 a trilogia foi lançada em DVD sob o título: Era Vargas 1930-1935 (ERA..., 2016). 
Grupos de imagens, como os cinejornais oficiais do regime varguista, são articulados com outros arquivos, tendo em conta os de imagens do cotidiano. A versão oficial dos cinejornais, com isso, passa a ser questionada. Esse cruzamento de imagens oficiais e não oficiais opera a construção de uma outra narrativa para a história, que também revela a reflexão sobre o processo de montagem.

No filme, o diário do ex-presidente não é apresentado apenas pelos fragmentos de suas imagens, mas também por meio da narração, interpretada por Eduardo Escorel. Na montagem dos cinejornais oficiais do regime varguista com os arquivos do diário íntimo de Getúlio Vargas, seus escritos são colocados como contraponto às imagens de arquivo dos cinejornais.

Na sequência de abertura (Figura 1), a primeira imagem que o filme apresenta é o recorte ampliado de uma carta datilografada por Alzira Vargas, filha do ex-presidente e Chefe de Gabinete Civil da Presidência da República. A correspondência é parte de um arquivo oficial em que Alzira narra o atentado ao Palácio da Guanabara - então residência do Presidente da República - por ação do Levante Integralista7, em oposição a Getúlio Vargas.

Nesse primeiro momento, a situação que a carta descreve - uma tentativa frustrada de derrubar o presidente e o caráter conspiratório da circunstância - não é mostrada. No entanto, a utilização dessa imagem mostra uma indagação a respeito do processo de montagem do filme. No excerto da carta, que ressurge em outros momentos da narrativa, há palavras entrecortadas, no qual lemos: “[...] que descobri. Eu não vi [...]” (IMAGENS..., 2016).

Figura 1 - Os fragmentos e a montagem como reelaboração da história

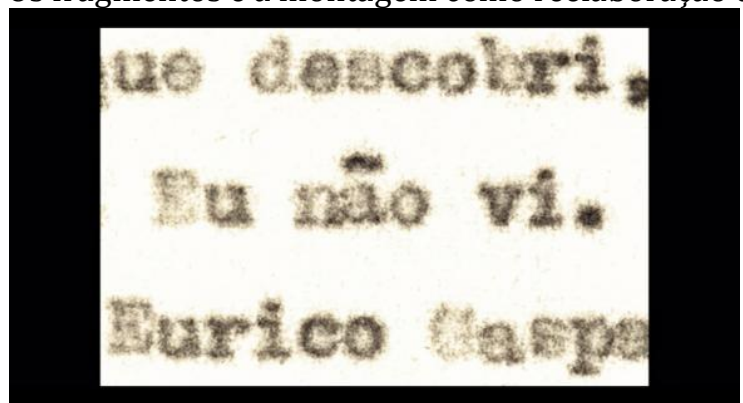

Fonte: Adaptado do filme de Escorel (IMAGENS..., 2016).

Nota: Tempo: 00:00:56

\footnotetext{
70 Integralismo foi um movimento de cárter autoritário que reuniu representantes militares e paramilitares da extremadireita brasileira. Os Integralistas apoiaram a formulação do golpe que instituiu o Estado Novo, visando à participação no Governo de Getúlio Vargas. Contudo, o estado de guerra promulgado pelo regime colocou partidos e associações de caráter político na clandestinidade. Inconformados com a ausência de sua atuação no governo, em 11 de maio de 1938 , os Integralistas sublevaram-se num ataque, malsucedido, com o objetivo de depor o Presidente (FAUSTO, 2006).
} 
Partindo da imagem da carta de Alzira Vargas, o filme mostra seu exercício de reelaboração da história com base nas conexões entre os fragmentos. A narrativa apresentase como uma versão e, com isso, coloca em questão as imagens oficiais do regime. Há um deslocamento constante entre o social e o íntimo, qual seja, entre as imagens oficiais, as imagens do cotidiano das ruas àquela época, o diário de Getúlio Vargas, e a própria reflexão da narrativa quando à sua montagem no tempo presente.

Junto ao trecho da carta da filha de Getúlio Vargas, a sequência é encadeada a um arquivo, que mostra um acontecimento do cotidiano da cidade: a ressaca do mar no Rio de Janeiro, à época, Capital Federal (Figura 2). A força das ondas incide sobre o cordão de proteção, que impede a invasão da água em uma região costeira da cidade. A articulação entre a carta e os movimentos do mar nos dá a ver uma narrativa que se produz pelo refluxo da história, ou seja, como a história se mostra no tempo presente.
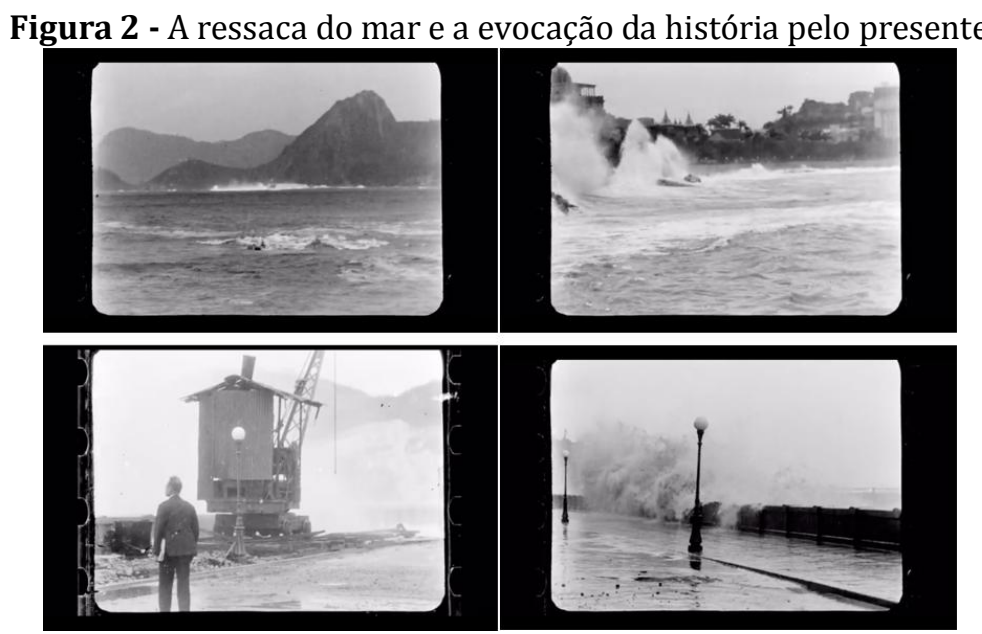

Fonte: Adaptado do filme de Escorel (IMAGENS..., 2016). Nota: Tempo: 00:00:58

As imagens da ressaca do mar são sincronizadas com uma marchinha de carnaval que diz: "Brasil, és no teu berço dourado, um índio civilizado e abençoado por Deus! Oh, meu Brasil! Oh meu Brasil, gigante de um continente, és terra de toda gente, orgulho dos filhos teus! Oh! Meu Brasil!" (IMAGENS..., 2016, doc. não paginado). A música carnavalesca sinaliza um elemento estético do qual o filme se vale de forma recorrente em seu processo de montagem, para propor um entendimento da ligação entre as políticas de Estado e o cotidiano brasileiro. 
As manifestações carnavalescas no filme sugerem um sentido, além da celebração festiva, de otimismo com as transformações políticas e sociais que o país vivia naquele momento. Também mostram uma certa normalidade no cotidiano da Capital, enquanto o Brasil vivenciava sua entrada na Segunda Guerra Mundial. As imagens do documentário revelam algo diferente do que é mostrado pelos filmes de propaganda varguista. Por exemplo, como é possível a ditadura do Estado Novo ter soldados lutando pela liberdade no exterior, enquanto o país estava sob um regime autoritário?

Desde a sequência da imagem da carta de Alzira Vargas (Figura 1), até a sequência do mar revolto (Figura 2), ao som da marchinha de carnaval, são reunidas fotografias de Getúlio Vargas posando para um escultor norte-americano, enviado pelo então presidente dos Estados Unidos, Franklin Roosevelt (Figura 3). 0 narrador introduz em sua locução fragmentos do diário de Getúlio Vargas, que descrevem o estado afetivo do então Presidente, revelando a sua contrariedade ao momento diante do escultor. Porém, as imagens mostram outro estado de espírito, o contentamento de Getúlio Vargas.

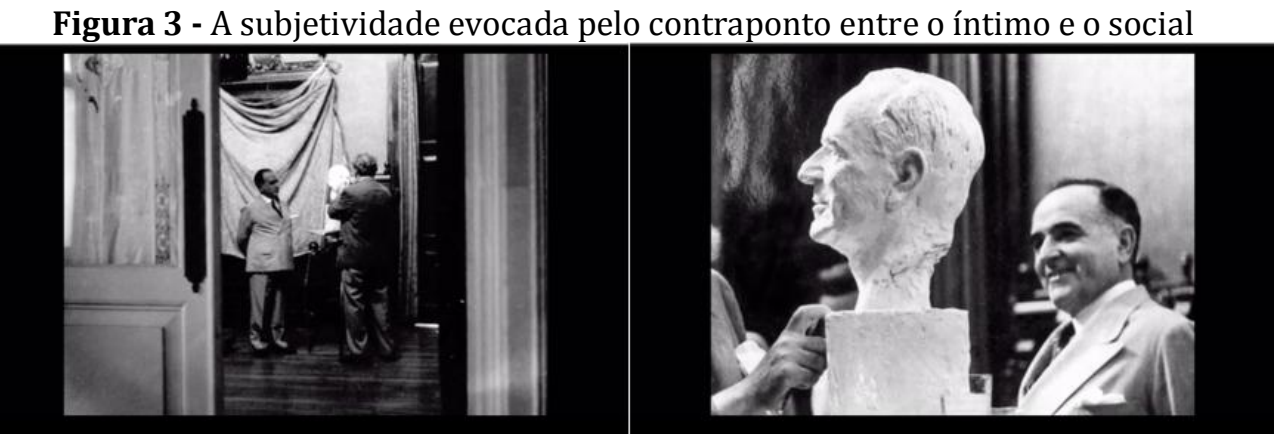

Fonte: Adaptado do filme de Escorel (IMAGENS..., 2016). Nota: Tempo: 00:02:08.

Outra sequência que releva as contradições entre as imagens e a narração de trechos do diário, é a do juramento de Getúlio Vargas perante à Assembleia Constituinte, comprometendo-se com a futura chamada para a eleição presidencial de $1938^{8}$. Nesse momento do filme (Figura 4), as imagens da posse são colocadas em contraponto ao diário de Getúlio. Por meio da voz do narrador, notamos que, para o Presidente, a nova Constituição configurava-se como um empecilho.

\footnotetext{
8 Em 1934, Getúlio Vargas é eleito Presidente por uma Assembleia Constituinte, marcando o final do Governo Provisório, instaurado com o a Revolução de 30. 0 Governo Constitucional, iniciado em 1934, tem fim em 1937, com o golpe civil-militar que dá início ao Estado Novo (FAUSTO, 2015).
} 
Figura 4 - As lacunas entre o oficial e o íntimo como recurso subjetivo da narrativa

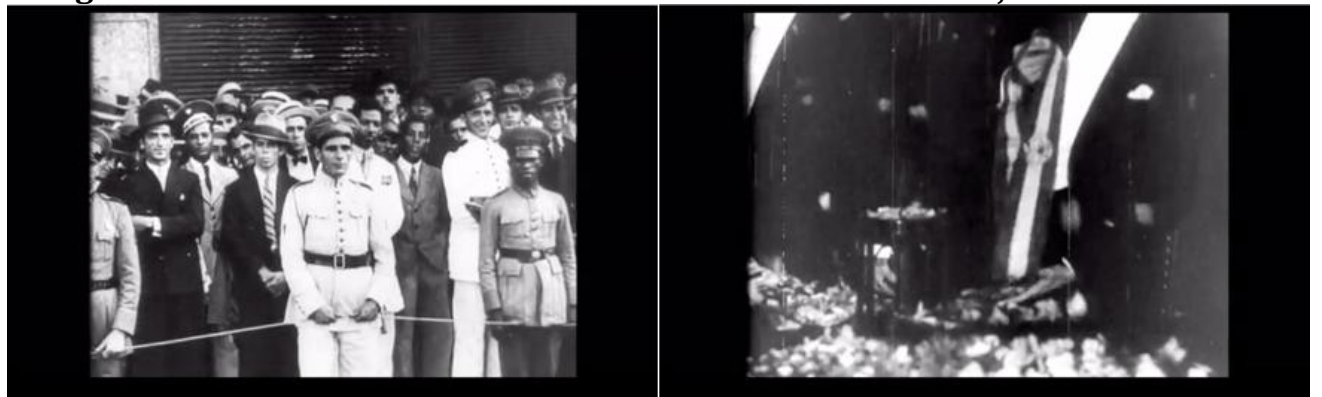

Fonte: Adaptado do filme de Escorel (IMAGENS..., 2016).

Nota: Tempo: 00:07:29.

A narrativa apresenta arquivos de cinejornais brasileiros, cujas imagens tornam evidentes a mobilização e o apoio popular a Getúlio Vargas (Figura 4) para, em seguida, questionar o valor do seu diário como fonte histórica. 0 narrador descreve uma passagem escrita pelo ex-Presidente em julho de 1934, evidenciando a preocupação do governante, que se pergunta quanto à lealdade daqueles que estavam junto a ele no seu ato de posse. Naquele dia, Getúlio assumiu a Presidência da República, nomeado pelos deputados da Assembleia Constituinte. Também jurou pela Constituição que convocaria eleições para o ano de 1938.

Ao colocar em questão a autenticidade do diário de Getúlio Vargas como fonte histórica, a montagem recorre às imagens de câmaras de arquivamento, papéis empilhados e caixas de armazenamento de arquivos (Figura 5).

Figura 5 - Vestígios da construção de uma versão sobre a história

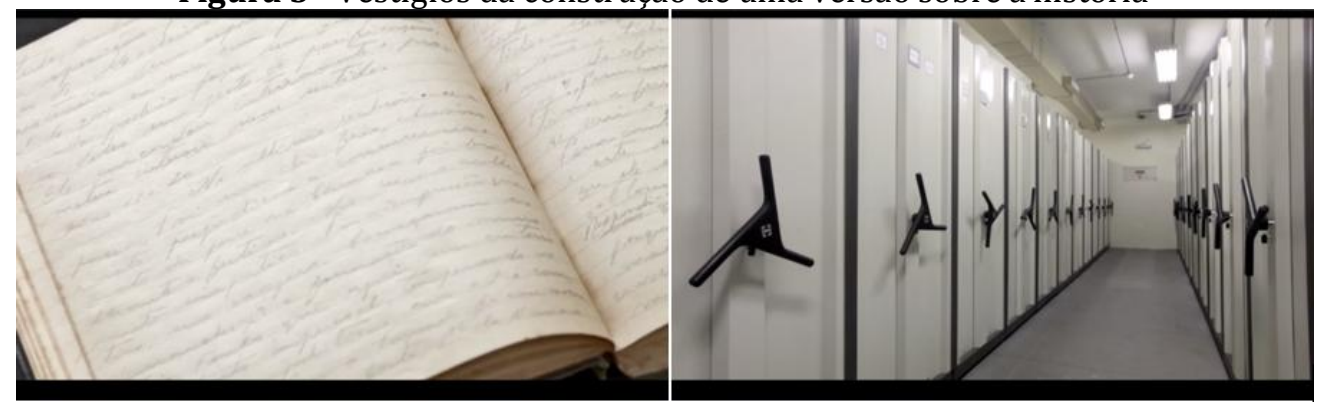

Fonte: Adaptado do filme de Escorel (IMAGENS..., 2016).

Nota: Tempo: 00:06:27.

Notamos que essas imagens são arquivos do próprio filme, ou seja, documentam o processo de pesquisa da narrativa e, sobretudo, mostram o mosaico que configura a montagem. Compreendemos que Imagens do Estado Novo 1937-45, assim como a história oficial, é uma versão que se apresenta por fragmentos. 0 filme revela os vestígios do seu 
processo de realização, mostrando o caráter lacunar dos arquivos e, também, os sentidos provisórios que assumem quando esse material é colocado em relação (IMAGENS..., 2016).

O caráter fragmentário das imagens é igualmente evidenciado pelo som. Simultaneamente às imagens dos cinejornais, aos trechos do diário pessoal de Getúlio Vargas e aos sons e imagens do carnaval de rua, a narrativa insere um filme do cotidiano de populares. Nele, os sujeitos posam para a câmera rodeados por uma matilha (Figura 6).

Figura 6 - 0 cotidiano revela-se nas versões da história

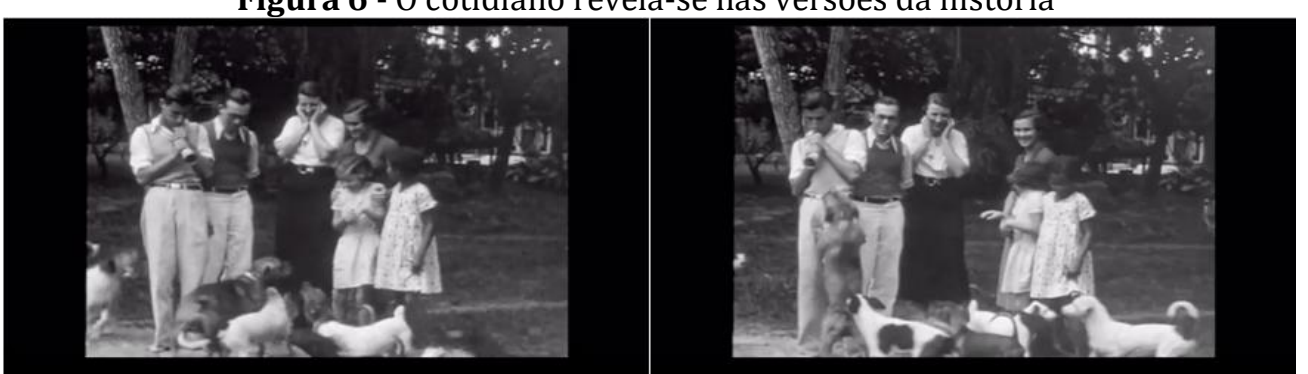

Fonte: Adaptado do filme de Escorel (IMAGENS..., 2016). Nota: Tempo: 00:12:45.

0 trivial de uma brincadeira, então, mescla-se aos fragmentos de filmes oficiais, ao diário pessoal e ao cotidiano festivo nas ruas. 0 homem toca seu instrumento musical enquanto, rodeado pelos cães, um de seus familiares protege os ouvidos. Portanto, a narrativa incide sobre o que é visto, porém não é ouvido e, também, naquilo que é ouvido, mas não é visto. Da mesma forma que a carta de Alzira Vargas, apresentada na sequência de abertura (Figura 1), a qual é mobilizada pela montagem em outros momentos do filme (Figura 7).

Figura 7 - Fragmentos de uma carta e a montagem de uma versão que questiona a história

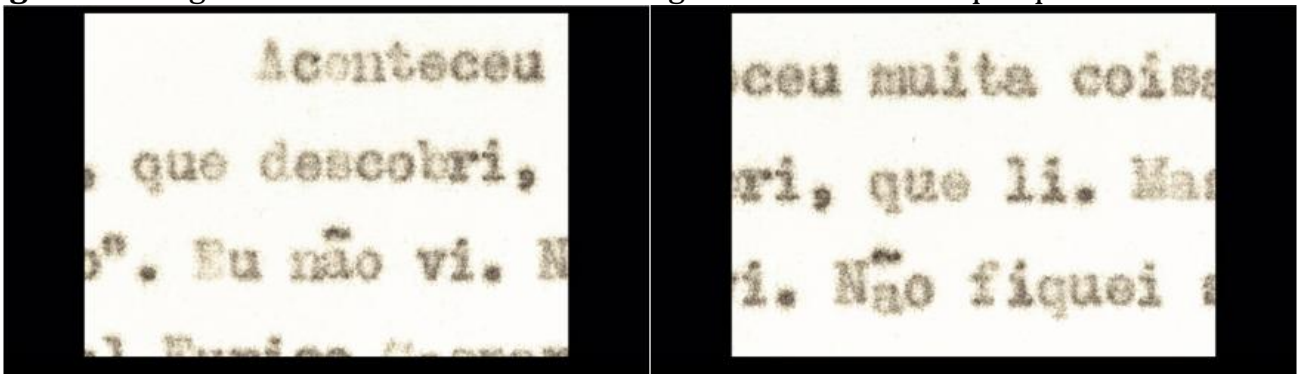

Fonte: Adaptado do filme de Escorel (IMAGENS..., 2016). Nota: Tempo: 01:05:34. 
O filme de Eduardo Escorel (IMAGENS..., 2016) contrapõe as evidências, partindo de um novo arranjo entre as imagens, provocando o pensamento quanto à validade dos discursos e as novas escrituras críticas da história. Sua montagem mostra que uma imagem instituída, como a de um cinejornal de governo, pode ser reconfigurada, produzindo uma tensão sobre o passado, de modo a questionar as versões da história no tempo presente.

Nessa narrativa, percebemos a naturalidade com que a Capital Federal recebe o golpe civil-militar que institui o Estado Novo. 0 comércio abre, as pessoas transitam pelas ruas, os bondes elétricos e os automóveis circulam, como em um dia qualquer. No ano em que Imagens do Estado Novo 1937-1945 foi lançado, o Brasil vivenciava um novo golpe contra a democracia. Assim como em 1937 e, também, no golpe civil-militar de 1964; no dia 31 de agosto de 2016, as ruas expressavam uma aparente normalidade. Desse modo, o filme dialoga com o seu tempo, pois trata do passado, possibilitando refletir o político e o social no presente.

O mostrar e o não mostrar no processo de narrativa também aparece através dos cinejornais estrangeiros. Eles são inseridos de forma a produzirem contextualizações do cenário político internacional, em interlocução com o regime ditatorial varguista. A ascensão dos regimes autoritários na Europa é mostrada, por exemplo, por meio de um cinejornal alemão, que celebra o avanço das tropas franquistas na cidade espanhola de Bilbao.

Na narração, Eduardo Escorel trata do massacre civil realizado pelo bombardeio à cidade de Guernica. Ao mencionar essa dizimação promovida por um esquadrão aéreo da Alemanha Nazista, alguns dias antes do avanço das tropas em Bilbao, o ecrã negro insere-se como recurso estético. 0 narrador questiona o fato de o cinejornal alemão não mencionar a barbárie em Guernica. Vê-se uma montagem que atua diante do que não é mostrado, em uma versão construída para a história oficial, nesse caso, o cinejornal Nazista. 
Figura 8 - Imagens oficiais construídas para a história, em contraponto ao que não é mostrado
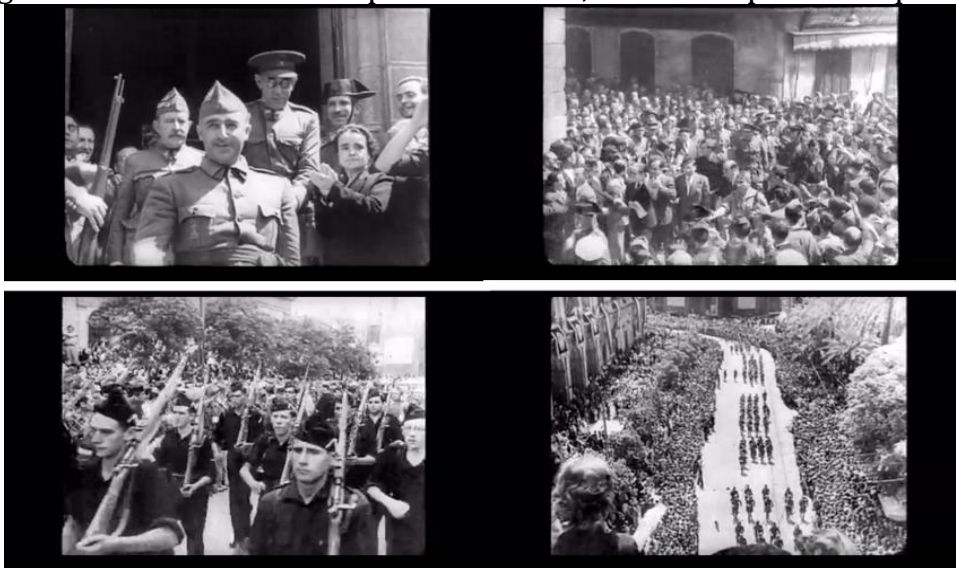

Fonte: Adaptado do filme de Escorel (IMAGENS..., 2016). Nota: Tempo: 00:13:00.

A interpretação que a montagem do filme oferece a respeito da omissão da brutalidade em Guernica - o uso do ecrã negro, a locução na qual o narrador menciona a ausência da repercussão do massacre na versão do cinejornal alemão - mescla-se às diferentes temporalidades da narrativa, quais sejam: a ausência de informações sobre o fato no manuscrito do diário de Getúlio Vargas, os cinejornais brasileiros que noticiam um certo entusiasmo do país junto ao seu líder político e, ainda, os arquivos de imagens do cotidiano. Articulados pela montagem, tais arquivos corroboram para a reflexão que o filme faz de sua própria construção narrativa da história e, simultaneamente, produz reconfigurações das imagens do Estado Novo brasileiro.

\section{Considerações finais}

A atualidade de Imagens do Estado Novo 1937-45 está em sua maneira de reelaborar um passado que sobrevém ao presente e de rememorar as sucessivas experiências de governos autoritários, partindo do Estado Novo.

As imagens e sons do filme tornam visíveis o momento histórico que ele narra, pois são fragmentos que atestam materialmente o que se passou na história, refletidos na melancolia dos seus desdobramentos no presente. Ou seja, essas imagens do passado atestam o que estamos vivendo na contemporaneidade, para além da compreensão do acontecimento histórico. Há, portanto, uma característica intrínseca ao filme em tratar do 
momento político presente, de modo adjacente à objetividade da temática apresentada por sua narrativa.

Nesse sentido, a análise da montagem do filme é uma forma de pensar a história e a relação entre imagem-narrativa, revelando a aproximação entre arquivos inscritos em diferentes temporalidades. Assim, a evocação do passado ocorre pela contingência manifestada na tentativa de se compreender a atualidade. Cada presente possui suas reverberações do passado e é nesse limiar entre o presente e o passado que acontece a história.

O diálogo do filme com o seu tempo está em mostrar a reconfiguração do passado por meio do cinema, como forma de pensar a atualização de fatos políticos. Isso fornece pistas de como são produzidas versões da história pela utilização de imagens e sons que, na atualidade, ao serem replicados pelas tecnologias digitais de compartilhamento, podem validar discursos e desdobramentos dos autoritarismos vivenciados no Brasil. A narrativa apresenta os arquivos como forma de pensar a experiência histórica, por isso, coloca em xeque os usos das imagens e dos sons.

O filme recorre aos arquivos do diário pessoal de Getúlio Vargas em contraponto à história oficial, e também à reflexão que produz de si, ao criar sua própria versão sobre a história. A narrativa coloca em evidência fatos históricos e cria tensões entre eles, pois o narrador destaca o processo de montagem como um arranjo de fragmentos que compõem sua própria visão do Estado Novo.

O filme mostra, ainda, as contradições entre os manuscritos íntimos do expresidente e os acontecimentos históricos. 0 narrador reflete quanto ao manuseio desses arquivos, as versões parciais da comunicação oficial e dos apontamentos pessoais de Vargas, evidenciando vestígios do processo de elaboração de sua narrativa, buscando mostrar que a história é feita de lacunas.

Para isso, torna visível seu material bruto, isto é, imagens de acervos e câmaras de arquivamento. Essas imagens revelam, sobretudo, diferentes possibilidades para a narrativa, apresentando o filme como uma interpretação, da mesma forma que a história oficial, colocando-a em questão e oferecendo-se como uma construção para pensar a atualidade do passado. 


\section{Financiamento}

O presente artigo foi realizado com apoio da Coordenação de Aperfeiçoamento de Pessoal de Nível Superior - Brasil (CAPES) - Código de Financiamento 001 e do Conselho Nacional de Pesquisa (CNPq).

\section{Referências}

BADIOU, A. Cinéma. Paris: Nova, 2010.

BAZIN, A. 0 que é o cinema? São Paulo: Cosac Naify, 2014.

BENJAMIN, W. Passagens. Belo Horizonte: UFMG, 2006.

DIDI-HUBERMAN, G. 0 que vemos, o que nos olha. 2. ed. São Paulo: Editora 34, 2010.

DIDI-HUBERMAN, G. Imagens apesar de tudo. Lisboa: KKYM, 2012.

ERA Vargas 1930-1935. Direção: Eduardo Escorel. [S. l.]: Brasil 1500, 2016. 3 DVDs (196 min), son., color. Legendas português/inglês.

FAUSTO, B. História concisa do Brasil. 3. ed. São Paulo: Edusp, 2015.

FAUSTO, B. Getúlio Vargas: o poder e o sorriso. São Paulo: Companhia das Letras, 2006.

GOMES, A. C. O Estado Novo e o debate sobre o populismo no Brasil. Sinais Sociais, Rio de Janeiro, v. 9, n. 25, p. 9-38, maio/ago. 2014.

IMAGENS do Estado Novo 1937-45. Direção: Eduardo Escorel. [S.l.]: Brasil 1500, 2016. Arquivo digital (225 min), son., p \& b; color.

KRACAUER, S. Historia: las últimas cosas antes de las últimas. Buenos Aires: Las Cuarenta, 2010.

KRACAUER, S. Teoria del cine. Barcelona: Paidós Ibérica, 2001.

PINEL, V. Écoles, genres et mouvements au cinéma. Paris: Larousse, 2000.

PINEL, V. Los géneros cinematográficos: genéros, escuelas, movimentos y corrientes del cine. Barcelona: Robinbook, 2008.

PINHEIRO, P. S. Transição política e não-estado de direito na República. In: PINHEIRO, P. S.; WILHEIM, J.; SACHS, I. (org.). Brasil: um século de transformações. São Paulo: Companhia das Letras, 2001. 


\title{
A film that thinks about itself: the politic and the fragments of history
}

\begin{abstract}
We analyzed the montage of Imagens do Estado Novo 1937-45, by Eduardo Escorel, with the aim of observing the actuality of the narrative, emphaticizing its political aspects. We examine how fragments of images used by the decoupage articulate the interaction between present time and images of Estado Novo. The subjectivity as a narrative trace shows the reflection that the film raises about itself through its narrator and the vestiges that reveal the process of montage of archives. The film elaborates a way of thinking the politic as a manifestation of history in the present time, by approaching facts that marked the first half of the twentieth century in Brazil.
\end{abstract}

\section{Keywords}

Politic Film. Brazilian Cinema. New State.

Recebido em 25/04/2018

Aceito em 24/09/2018 